\title{
A Handbook for Tailoring Craftsmanship Industries. Communicate the Intangible Values of Traditional Methods through Images ${ }^{+}$
}

\author{
Maria D’Uonno \\ Department of Architecture and Industrial Design, Università degli Studi Della Campania Luigi Vanvitelli, \\ 81031 Aversa, Italy; maria.duonno@gmail.com; Tel.: +39-333-7194-733 \\ + Presented at the International and Interdisciplinary Conference IMMAGINI? Image and Imagination \\ between Representation, Communication, Education and Psychology, Brixen, Italy, 27-28 November 2017.
}

Published: 20 November 2017

\begin{abstract}
For centuries, Neapolitan tailors - as many others - have been verbally transmitting their technical know-how to their younger apprentices, who were later to become masters themselves in an arguably uninterrupted cycle. My prime focus is to provide contemporary tailors with a method to pursue this goal, which is one compatible with modern tailoring production processes. Is it possible for an illustrated tailoring handbook to take care of the lack of time, that was once a necessary ingredient to the successful transmission of traditional Neapolitan tailoring rules? Manuale di Sartoria Kiton is the result of my thesis project, discussed at the end of my MA in Visual and Communication Design at IUAV University of Venice, in 2015. The thesis project is focused on Kiton tailoring company, based in Naples. During my internship at Kiton, I had the opportunity to document the company's tailoring methods. According to my thesis, the images contained in a tailoring manual can be used as ideal mediums to turn intangible slow-training phases into tangible objects, virtually always available for future reference. The proposed handbook therefore carefully illustrates the Neapolitan bespoke jacket sewing process, with both technical and descriptive drawings. Thus, images serve as a communication tool and a visual aid for the masters and their apprentices, allowing to overcome even occasional language barriers.
\end{abstract}

Keywords: Heritage; craftsmanship; know-how; cognitive drawing; tradition; translation; illustrations

\section{Introduction}

In Naples, tailoring companies are strongly linked to traditional Neapolitan craftsmanship. International firms like Kiton, Attolini, Cilento, Isaia, and Rubinacci arose like craftsman shops and only later turned into business companies. They were able to achieve this transition investing considerable resources in an attempt to preserve the craftsman know-how, combining innovation and traditional methods into a hybrid production chain. In this working environment machines operate alongside experienced tailors in order to ensure high quality standards while speeding up production.

Kiton is the chosen case study as it represents the typical local craftsmanship industry. Founded by Ciro Paone in 1968 [1]. The company has different laboratories, one for each item of clothing. The jacket laboratory alone employs more than 300 tailors, divided into specialized groups and it is capable of producing 80 jackets in one day.

Such a high number of tailors demand for many young apprentices ready to replace the old generation. To cope with this issue, Kiton started a short school program led by senior tailors where students undergo a two years training, primarily focusing on the jacket. 
The tailoring notions were traditionally transmitted from one generation to the next through verbal teaching. Usually, the apprenticeship lasted between five and ten years. The senior tailor, usually called Masto, had to train the young apprentices - almost always children-into his workshop.

How can we train tomorrow's craftsmen without a real atelier experience? How can we give them a workshop expertise in a very short time?

An illustrated handbook can be a valid tool for the beginners during their training as it can clearly show the main rules. Manuale di Sartoria Kiton (Figure 1).

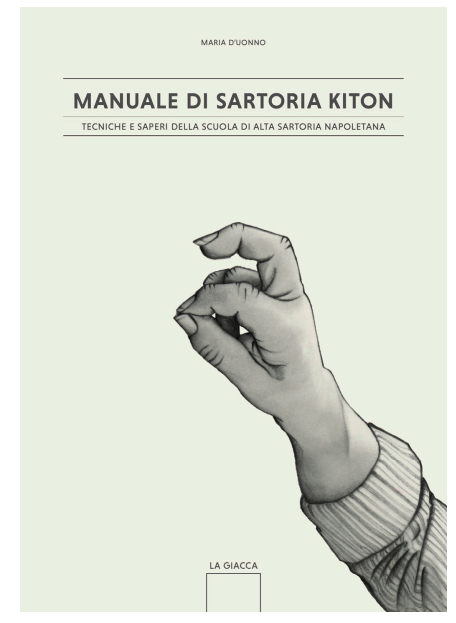

Figure 1. Manuale di Sartoria Kiton, the result of my thesis project, discussed at the end of my MA in Visual and Communication Design at IUAV University of Venice, in 2015.

The project includes a historic Neapolitan tailoring background based on literature review, followed by an analysis of historic tailoring manuals and methodological observations.

A professional internship at Kiton's headquarters gave me the opportunity to gather information about their tailoring rules, the production chain organization and the aforementioned Kiton's tailoring school.

\section{Brief History of Tailoring Craftsmanship in Naples}

By setting as its power values the extraordinary craftsmanship and the ability to realize high-quality products, Neapolitan tailoring gained worldwide fame, contributing to the success of the Made in Italy phenomenon that saw Italian fashion spreading into the world [2].

The history of Neapolitan tailoring starts in 1351 when the Confraternita dell'Arte dei Giubbonai e dei Cositori (Jacket Makers' and Tailors' Brotherhood) was founded. The main purpose of the brotherhood was to consolidate Neapolitan tailoring techniques.

In 1611 the brotherhood recognised 607 tailors and gave them authorization to work in Regno delle Due Sicilie [3].

After the Unification of Italy, Raffaele Sardonelli and Filippo De Nicola established their own style based on the tailor's skills and high-quality fabrics. Filippo's heir, Adolfo after training in his father's workshop sets on a formative journey to England. Upon his return to Naples he inevitably started to merge English style-characterized by severe lines and thick lining-and Neapolitan typical creativity in his own creations. The results were precious outfits, characterized by pure lines that suited the aristocracy and high middle-class taste; to the point that Adolfo De Nicola was chosen as royal tailor by Vittorio Emanuele III during his kingdom [4].

At the beginning of XX century, new tailors came to light, carrying innovation to the established tailoring know-how.

Peppino Miniello was the first tailor to experiment longer darts on the jacket's front (Figure 2). Thanks to this feature, his jackets better followed the bodylines. This detail became one of the elements that still characterize the Neapolitan jacket today. 


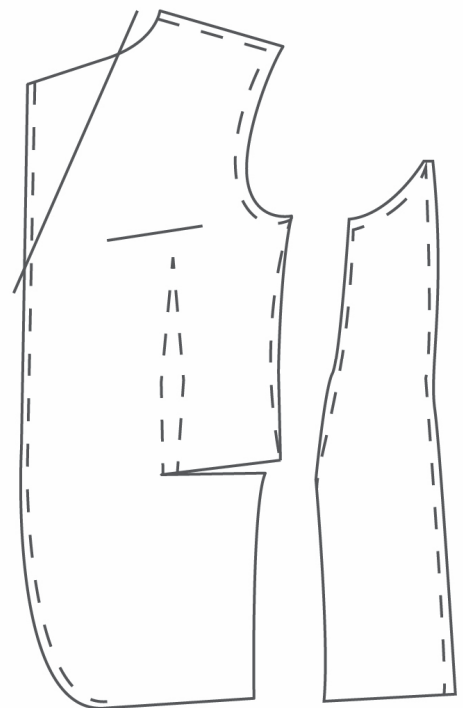

(a)

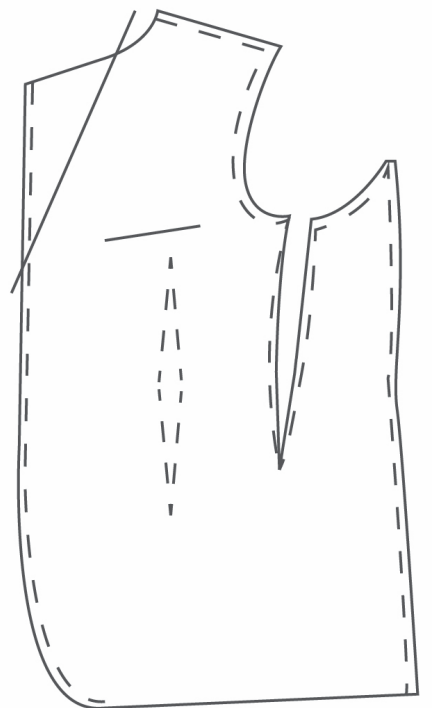

(b)

Figure 2. (a) long darts on the jacket's front; (b) short darts on the jacket's front.

In 1887, Antonio Caggiula published L'arte del taglio. Libro per i maestri-sarti, the first Neapolitan tailoring manual. Inside the book, theoretical formulations are backed up by patterns (A pattern is the template from which the parts of a suit are traced onto fabric before being cut out and assembled.) and illustrations of current suits. The book became an important treaty and the Ministry of Education bought 300 copies that were sent to libraries and professional schools [4]. At the beginning of XX century Antonio Caggiula opened his own tailoring school, in which he has been an active teacher for almost 50 years.

Angelo Blasi was another tailor that spent most of his the energy for Neapolitan tailoring movement, establishing in 1954 the association called Circolo Mediterraneo dei Sarti which had the same purpose of the above mentioned brotherhood. In 1956 the association's press service La Voce dei Sarti published its first issue.

However, the contemporary Neapolitan jacket owes its greatest innovations to the work of Vincenzo Attolini. The jacket revolution began when Vincenzo was employed as main cutter in the renowned London House tailoring workshop, in Naples. Before, the jacket appearance used to be austere and the lining (extra cotton layer, especially used in cold weathers) was applied according to the British tailor rules imported in Naples years ago.

Attolini deconstructed the jacket taking off most of the lining, and designed the soft-tailored jacket, making his suits even more comfortable to wear. He also introduced distinctive Neapolitan jacket details, such as the typical soft shoulders called a mappina and the small oblique pocket on the chest called a barchetta (Figure 3).

To date, Attolini's second skin jacket is recognised by the vast majority of Neapolitan tailors as the modern jacket [5]. 


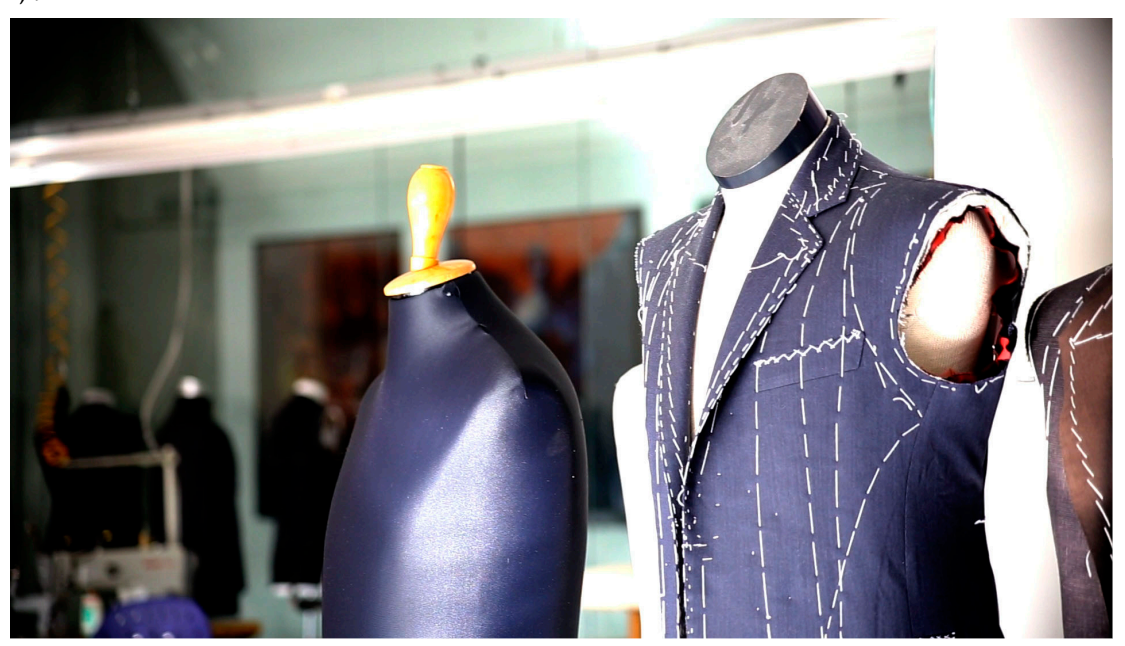

Figure 3. Kiton's tailoring school's jacket. Arzano (NA) 16 October 2015.

\section{The Last Generation of Workshop Trained Tailors}

Gianluca Migliarotti is a director and producer known for A Knife Life (2015), O'mast (2011) and Lino Sabattini (2010). The documentary O'mast is a collection of interviews made to the main representatives of Neapolitan tailoring today (Renato Ciardi, Pasquale Sabino, Antonio Panico, Ciro Palermo and Mariano Rubinacci among others). During the conversations, the tailors depict the typical tailor's training experience in Naples.

Between '30s and '70s, the training started in the family-run tailoring workshops when the apprentices were just children. The knowledge was transmitted from the Masto to his sons and apprentices.

The training first step was the careful observation of the Masto at work: the apprentice had to understand how to properly handle fabrics and acquire a refined dexterity, then they could start to thread the needle and similar little works. Before starting to work on real jackets they were trained how to sew correctly on simple pieces of fabric. The lessons often took place after the workshop shut down, until late at night. Usually, the apprenticeship could last for as long as ten years. The training ended when the apprentice finally became sarto imparato (learned tailor), when he was capable to craft all the classical items of clothing: jacket, tight, tails, coat and the cloak.

Since today's apprentices-with a few rare exceptions-can only start their training during high school or even later, they only have little time to learn. Therefore, this kind of training it's no longer possible.

\section{Historic Tailoring Manuals Review}

(ITA) “(...) Manuali, divenuti un tempo talmente popolari da condizionare i sarti a cucire le tasche esterne delle giacche maschili nella misura di undici per sedici centimetri, in modo da contenere un Manuale." (Assirelli, 1992: 2).

(ENG) "(...) Manuals, which became so popular that they started to influence tailors in making the external pockets on the men's jackets large enough to contain one of them: eleven by sixteen centimetres." (Assirelli, 1992: 2).

The presented manuals are Antonio Caggiula's L'arte del taglio. Libro per i maestri-sarti and Domenico Caraceni's Orientamenti nuovi nella tecnica e nell'arte del sarto.

The review focused primarily on two parallel tracks: understanding what needs let the authors feel that their manuals were necessary, while on the other hand analyzing the books' structures, the use of images and the pages layout.

Antonio Caggiula's father, Luigi Caggiula was a successful tailor in 1870. Antonio grew-up in his father's shop in Naples where he assimilated the tailoring rules and later exposed them into his manual in 1887 (Figure 4). 


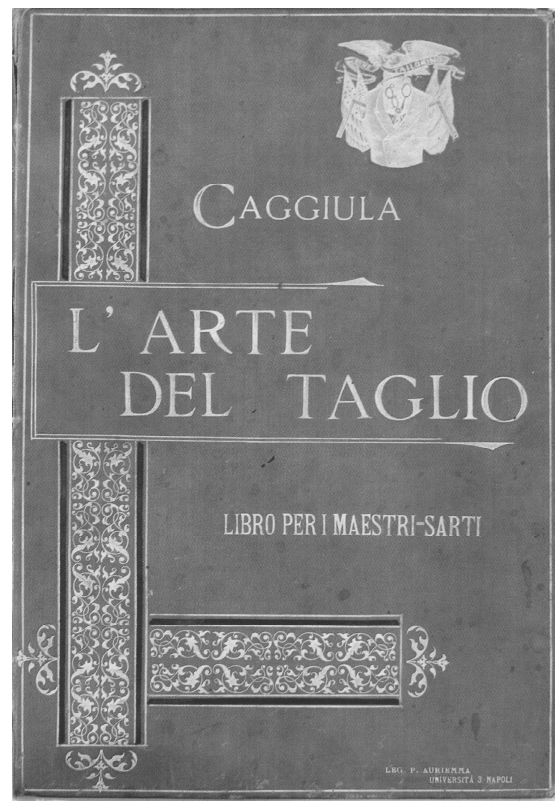

Figure 4. Caggiula, Antonio. L'arte del taglio. Libro per i maestri-sarti, Stabil. Tipografico dei F.lli Ferrante, Napoli, 1887.

By the end of XIX century each tailor shop in Naples had his own way to practice. This sometimes caused confusion and misunderstanding. The author intended to reorder the Neapolitan tailoring rules and delineate a method, starting from the critical tailoring issue: how to measure the human body.

Caggiula takes the Compaign Proportion-a new method based on a scale proportion used beyond the Alps and formulated by Guglielmo Compaign-as a starting point. He considers the Compaign Proportion a good experiment and a valid exercise to let the apprentices practice the pattern drawing, but he criticizes its lack of flexibility and excessive abstraction. In fact, according to Caggiula each individual had its own proportions, therefore each required a specific measurements.

(ITA) "... siamo venuti a sintetizzare il nostro metodo in poche misure affatto nuove, sulle quali sviluppare il disegno geometrico. Disegno, costante nella forma, semplice nel modo, (ma) suscettibile di infinite variazioni, per quanto indefinito è il prodotto delle misure del corpo umano." [6] (p. 7).

(ENG) "... we managed to synthesize our method in a few measurements-not at all new-upon which we can unfold the main geometrical drawing. This will be a drawing that is consistent in its form, simple in style, (but) easily adaptable to plenty of variations in order to support the infinite number of possible human body measurements." [6] (p. 7).

He ultimately defined his own method by the use of-only-eleven measurements, taken directly from the client's specific anatomy.

The manual's 150 pages are $30 \mathrm{~cm}$ tall and $24.4 \mathrm{~cm}$ wide. It is divided in two sections: the first one exposes the method's theoretical apparatus. Technical drawings, illustrations and examples from the Compaign Proportion appear in the second section.

The first section is structured in paragraphs, each one explaining a different topic. These are illustrated following a tailor's logic sequence, starting with the measurement method to the pattern drawing rules. The pattern drawing process is explained by the author with step by step written instructions for all the fundamental items of clothing such as jacket, trousers, tight and tails.

The second section collects drawings as results or examples to further explain the written instructions exposed and cross referenced in the first section.

The choice to divide text and drawings in two different sections doesn't help a fast connection between explanations and images. In addition, the patterns are only shown entirely, without a series of images explaining the different drawing phases. 
Domenico Caraceni trained in his father's tailor shop [7] in Abruzzo, an Italian central region. He wrote Orientamenti nuovi nella tecnica e nell'arte del sarto in 1933, motivated by patriotic feelings and in order to claim a recognizable Italian fashion [8] (Figure 5).

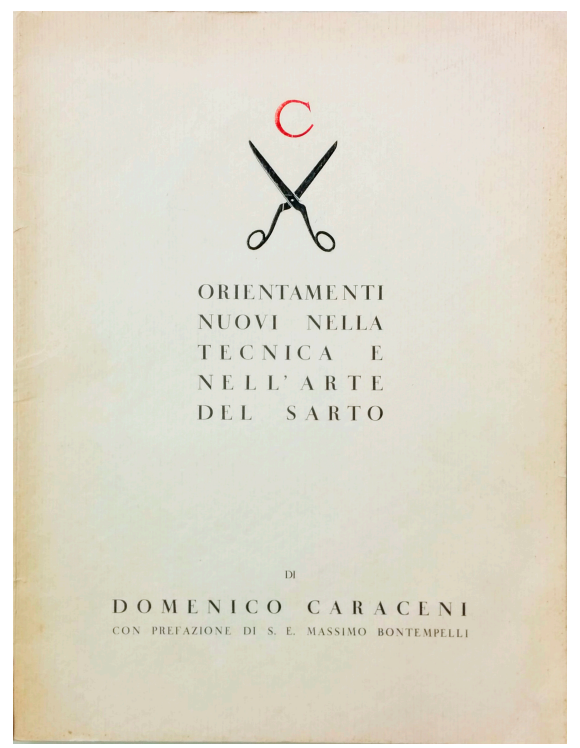

Figure 5. Caraceni, Domenico. Orientamenti nuovi nella tecnica e nell'arte del sarto. Preface by S.e. Massimo Bontempelli. Tipografia a Cav. D. Squarci \& Figli, Roma, 1933.

Caraceni also wanted to improve the bodylines measuring method and patented a machine for this purpose (Patent No. 286482). The measurement method is based on a polar coordinates system. The system allowed to calculate the distance of each point from its pole. The machine was made up by a graded and flexible quadrant through which center passed a vertical rod and the needed number of measuring tapes [9] (Figure 6).

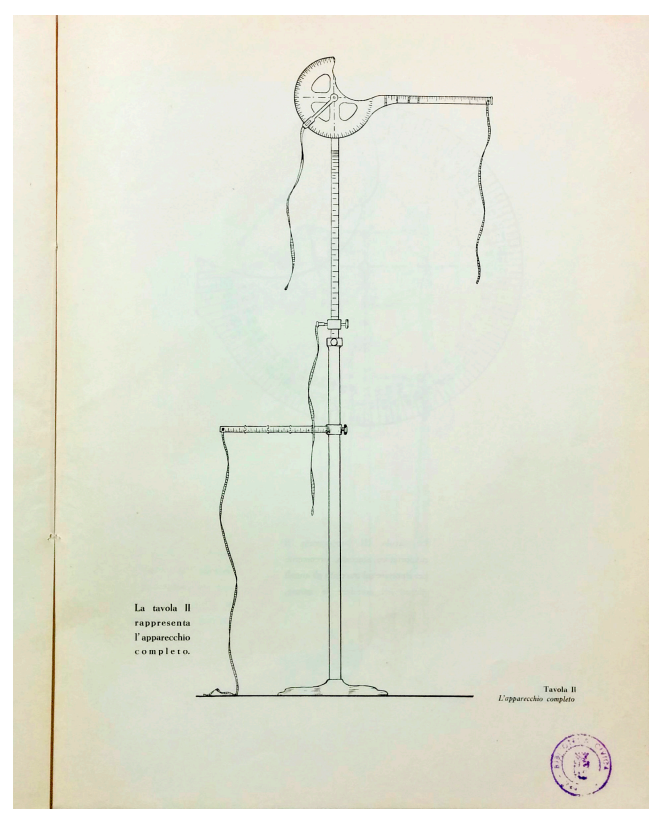

Figure 6. Caraceni's measurement machine illustration (Caraceni, 1933 p. 27).

The manual wants to be a scientific essay, a book of human geometry [8] for experts tailors willing to extend their own knowledge. The technique and measurement tools answered to the modern vision of a new tailors' generation, annoyed by approximated drawings and the old measurement methods inaccuracy [9]. 
According to Caraceni the suit had to be the result of rational thought and it had to follow the bodylines in order to ease the movements of modern, dynamic man. It is interesting to notice that Caraceni's comfort idea is very close to the one at the base of the later Attolini's jacket revolution.

The manual, and its 135 pages dimensions are $32.5 \mathrm{~cm}$ by $24.4 \mathrm{~cm}$. It is opened by a Massimo Bontempelli's preface and is divided in two sections. In the first section Caraceni explains-with the help of detailed technical illustrations-how to use his machine to measure a human body and how to translate these measurements into a technical pattern, which will later be used to cut the jacket parts off the fabric. In this case, the appearance of images next to the written instructions makes the explanation easy to follow through.

In the second section Caraceni explains his own patriotic idea of a tailoring discipline and his hope that innovation will help preserving the tailoring craftsmanship and contribute to create an original Italian fashion.

Other than the abovementioned tailoring manuals, my research also focused on the analysis of two, less didactic, operative manuals:

- Neufert, E., \& Neufert, P. (2012). Neufert Architects' Data, Fourth Edition (4 edition). Chichester,

West Sussex, UK; Ames, Iowa: Wiley-Blackwell [10]; (Figure 7a)

- $\quad$ Billy instructions manual by Ikea. (Figure 7b)

These have been chosen because they represent two extremes: the first being characterized by an articulate internal structure, while the second is based on a very simple and intuitive layout.

Architect's Data has been first published-in German-in 1936. In the following years it has been translated into 17 languages, it reached its 39th edition. The book rationally arranges notions and parameters useful to the standardized design of all the building's fundamental elements-wall, window, furniture, etc. - and entire building typologies-hospitals, theatres, schools, etc. In order to contain the shear amount of data, this manual's structure needs to be subdivided in chapters and sub-chapters, each focusing on the different topics with the careful use of text, schemes, technical drawings, tables and graphs. The presence of a detailed table of contents and running headlines makes it easier to navigate through the conspicuous number of arguments.

The second analysed manual is an instruction booklet provided with an Ikea piece of furniture, capable of exposing all the product construction phases with extreme simplicity and without the need for explanatory text, with all the subsequent cross-cultural benefits.

The selected examples are meant to give a broad view on the entire gamma of expressive possibilities different manuals can adopt in order to satisfy specific needs. Manuale di Sartoria Kiton stands roughly in the middle of these two extremes, seeking for a fair equilibrium between text and images that tend to complement one-another in order to transmit the most clear and simple possible information.

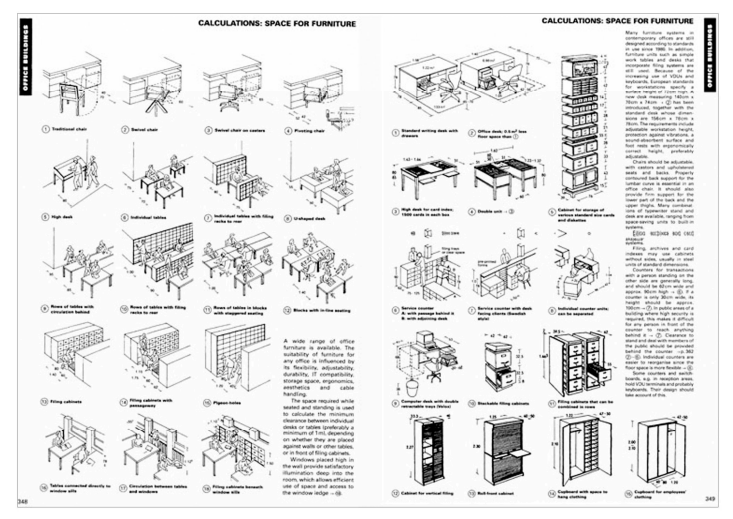

(a)
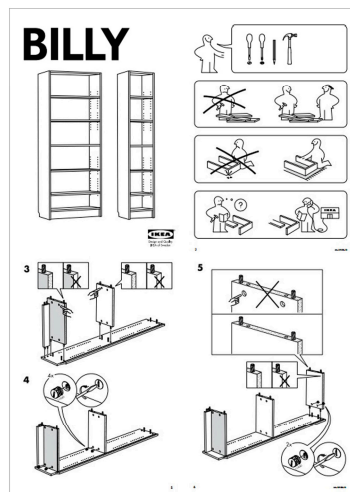

(b)

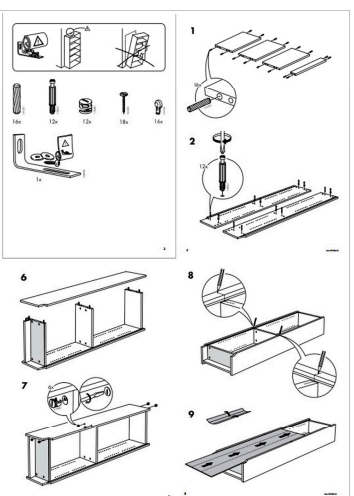

Figure 7. (a) Two-page spread from Architects' Data, from: http://pablogilcornaro.blogspot.it/ 2012/03/neufert-architects-data.html; (b) Ikea's Billy furniture instructions unfolded, from: http:// www.writingfordesigners.com/?p=19942. 
Further research could regard the study of didactic manuals dealing with different fields. In the present paper we only present the study manuals concerning pattern making and tailoring except for the two extreme examples mentioned above.

It could also be very interesting to investigate different didactic manual typologies, to study the relative design choices, what tools have been used in order to display information.

\section{Notes from the Kiton Experience}

Traditionally, as we said, the Neapolitan tailoring rules have always been handed down verbally. In Naples each tailor has his own method and trade tricks. For the expert's eye, it is easy to recognize a suit made by a certain tailor without the need to look at the label.

For this reason, the manual couldn't contain generic rules but it had to relate to a tailoring reality in particular. Kiton has been selected among others for the following reasons: Kiton hosts a tailoring school and it is one of the local craftsmanship industries with an interesting production organization, in which traditional craftsmanship rules and innovation are mixed.

My experience in Kiton's production facility was aimed at collecting information through conversations with the tailors, with their supervisors, with the head pattern maker, with school's teaching tailors and of course with the young apprentices. On the side, I also analysed the main production chain structure with particular attention to the jacket tailoring process.

The most demanding research endeavor has been the comprehension of the entire jacket production chain, keeping track of all the procedures and questioning all the tailors, in order to understand what their duties were and how they fulfilled them. Following a single jacket through the production chain (Figure 8) took four days of documentation. For the manual, the resulting material has been translated into technical drawings and illustrations.

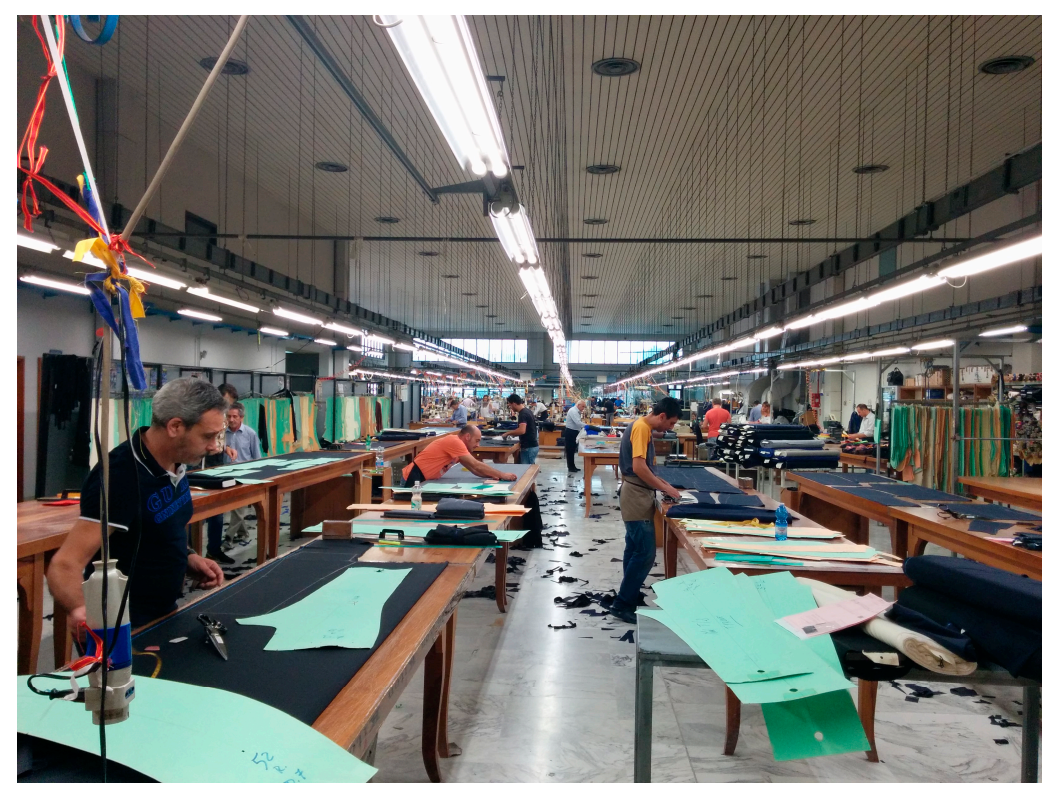

Figure 8. Tailors cutting the patterns of suits. Arzano (NA) 7 September 2015.

In Kiton's textile warehouse I had access to the company's fabric stock. Here, the supervisor explained the characteristics of different kinds of fabric and their behavior. In this occasion I had the opportunity to understand how important the raw materials knowledge and handling techniques are, which lead me to introduce a specialized chapter on the matter in the handbook.

Speaking with Kiton's school teaching tailors has been crucial for me to understand the limits of their apprentices' short training. Here, the typical student undergoes a two years training period-therefore very limited if compared to the traditional workshop training-focusing only on the jacket tailoring process. Which results in the impossibility for any apprentice to become a proper sarto imparato. 
One fundamental finding, coming from the conversations with the students, was that-out of necessity - the apprentices (It may also be interesting to note that-at least among this limited 20 students sample, equally divided into males and females - this practice was carried out exclusively by female students. The ones that would have virtually been precluded from the tailoring profession because gender biases.) often used to spontaneously collect notions and practical instructions on their personal tailoring diary, where they took notes about what they were learning in the form of writing and sketches.

\section{Kiton's Tailoring Manual}

The collected information was organized in schemes and flowcharts. All the tailoring items were analyzed and translated into images associated with text.

Kiton's tailoring manual is 221 pages, pocket-sized handbook (ISO A5: $148 \mathrm{~cm} \times 210 \mathrm{~cm}$ ) so to easily fit in the students' overalls pockets. The paper used to print the manual pages is light ( $90 \mathrm{gr})$ in order to contain the handbook weight inside the pockets. The binding is sewed to make the manual stronger.

On the cover, the title appears above an illustration showing the correct position for a hand to hold a needle (Figure 1), which is usually the first lesson a tailor apprentice used to learn in the master's workshop.

The manual is divided into five chapters:

- $\quad$ Le Misure-(The Measurements)

- Il Disegno del Tracciato-(The Pattern Layout)

- Materie Prime-(Raw Materials)

- Il Tracciato Della Giacca-The Jacket Pattern

- La Giacca Napoletana-The Neapolitan Jacket

In each chapter tailoring notions and rules are exposed through text, technical drawings and illustrations. The first three sections have the aim to introduce the apprentice to the tailoring world starting from the basics.

The measurements section contains notions about general anatomy and different body types. This way, the student can understand how the human body is articulated and how a tailor has to approach it. Anatomy related information is exposed through human body illustrations showing muscles and skeleton. Illustrations go with more detailed text. Different body types illustrations show the possible body flaws that a tailor has to take care of when drawing the suit's pattern. At the end of the measurements chapter, images of a man's silhouette show which measurements the tailor needs to take and how to take them, in order to draw a jacket pattern.

The pattern chapter introduces the basic notions to understand what a tailoring pattern is and how it relates to a human body through proportions grids. The chapter also illustrates the correct posture a tailor needs to get into when drawing the pattern and the tools needed to draw it.

The raw materials chapter describes the basic fabrics behavior and how to use them. Knowing the fabrics means knowing the fibers they are composed by. The manual shows the origin and the characteristics of fibers with schemes and maps. Technical drawings illustrate the composition of a piece of fabric: warp, weft, selvedge, what grain line is, right side and wrong side. Finally, a little glossary provides with more details on the fabrics and their origins.

The jacket pattern chapter illustrates step by step how to draw both the patterns of the one-breasted and the double-breasted jacket. To better understand the drawings, a legend is placed at the beginning of the chapter, explaining the meaning of icons and line types that make up the patterns. The technical drawings illustrate the entire procedure and are always followed by written instructions. Pattern variations related to different body types conclude the chapter.

The Neapolitan Jacket's is the final chapter. It starts with an introduction of tailoring tools and the explanation of sewing stitches. It explains how to arrange a pattern on a piece the fabric, how to cut the pieces and assemble them (Figure 9). It was necessary to introduce a legend illustrating the different kinds of symbols, colors and weight lines indicating different tailoring steps in the images. 


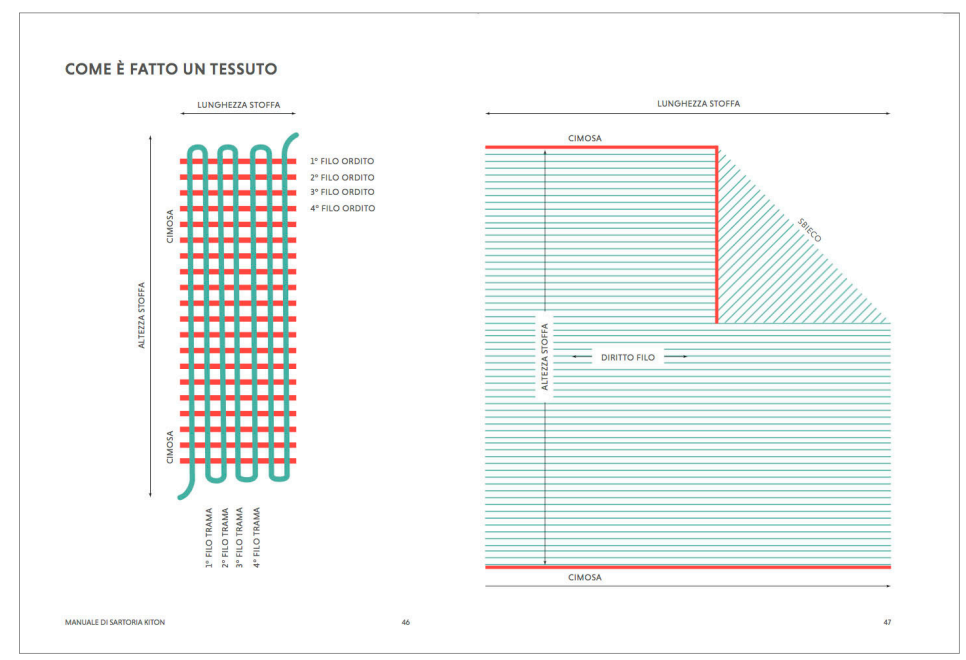

Figure 9. Technical drawing designed for the raw material chapter. Fabric notions.

The main book design decisions - the manual's contents arrangement and a visual oriented explanation strategy - are meant to respond to the questions raised in the paper's introduction: How can we train tomorrow's craftsmen without a real atelier experience? How can we give them a workshop expertise in a very short time?

The contents are in fact displayed following a sequence comparable to that presented to the learning process of a traditional apprentice in his master's atelier: first comes the observation, and only after is the apprentice allowed to start practicing the tailoring art and fine-tuning his craftsmanship skills.

For this reason, in the first chapters of the book, the student observes the images in order to acquire the basic tailoring notions: recognizing body differences among different clients, understanding the relationship between the human figure and the patterns, different sewing techniques, and how the needle should be properly held. Only after, in the second part of the manual, the student is invited to apply the method and put into practice what has been previously observed. Within the manual this is achieved through the jacket tailoring exercise, from the pattern layout to the last stitch.

Therefore, if we believe to be true that past apprentices used to learn by the means of theft with their eyes, the manual goal is to provide the modern students with images that show anatomical notions, gestures, geometrical drawings and tools in order to give them an experience that is as close as possible to the workshop training process.

Inside the book, images represent most of the content and take on the challenge to ease the notions understanding, overcoming language barriers as much as possible.

Different drawing communication needs are satisfied with different drawing techniques: gestures are represented via the use of illustrations, jacket patterns with geometrical drawings, the tailoring phases with flat drawings. Text is mostly used in the form of caption except for a few exceptions, such as in the Raw Materials chapter or in the chapters' introductions.

There is no doubt that only practice and the will to perfect one's technique will turn the apprentice into a sarto imparato (learned tailor). The manual is only meant to acts as a virtual companion in the learning process.

All images, in lack of a different specification are produced by the author: Maria D'Uonno.

Acknowledgments: I would like to thank-in alphabetical order-Alessandra Cirafici, Caterina Cristina Fiorentino and Federico Letizia and Erica Zipoli for their invaluable support.

Conflicts of Interest: The authors declare no conflict of interest. The founding sponsors had no role in the design of the study; in the collection, analyses, or interpretation of data; in the writing of the manuscript, and in the decision to publish the results. 


\section{References}

1. Cuciniello, M.; Maresca, M. Kiton; Mondadori Electa: Milano, Italy, 2007; ISBN 978-88-370-4086-4.

2. Frisa, M.L.; Mattirolo, A.; Tonchi, S. (Eds.) Bellissima: L'italia Dell'alta Moda, 1945-1968; Electa, MAXXI: Milano, Italy; Roma, Italy, 2014; ISBN 978-88-370-9923-7.

3. Jin, B.; Cedrola, E. (Eds.) Fashion Branding and Communication: Core Strategies of European Luxury Brands; Palgrave Macmillan: New York, NY, USA, 2017; ISBN 978-1-137-52342-6.

4. Taglialatela, M.A. (Ed.) La Creatività Sartoriale Campana; Arte'm: Napoli, Italy, 2010; ISBN 978-88569-0145-0.

5. Migliarotti, G. O'Mast; Kid Dandy: Milano, Italy, 2011.

6. Caggiula, A. L'arte del Taglio. Libro per i Maestri-Sarti; Lavoro Corredato da Oltre 190 Modelli; Stabil. Tipografico dei F.lli Ferrante: Napoli, Italy, 1887.

7. Vergani, G. Sarti d'Abruzzo. Le Botteghe di ieri e di Oggi Protagoniste del Vestire Maschili; Skira Editore: Milano, Italy, 2004; ISBN 978-88-8491-595-5.

8. Caraceni, D. Orientamenti Nuovi Nella Tecnica e Nell'arte del Sarto, preface by S.e. Massimo Bontempelli; Tipografia a Cav. D. Squarci \& Figli: Roma, Italy, 1933.

9. Lupano, M.; Vaccari, A. (Eds.) Una Giornata Moderna. Moda e Stili Nell'italia Fascista; Damiani Editori: Bologna, Italy, 2009; ISBN 978-88-6208-061-3.

10. Neufert, E.; Neufert, P. Neufert Architects' Data, 4th ed.; Wiley-Blackwell: Chichester, UK; Ames, IA, USA, 2012.

(C) 2017 by the author. Licensee MDPI, Basel, Switzerland. This article is an open access article distributed under the terms and conditions of the Creative Commons Attribution (CC BY) license (http://creativecommons.org/licenses/by/4.0/). 